\title{
An astonishing simple cerium-based chemosensor for fluorescent selective phosphate detection in aquaeous medium
}

\author{
Thibaud Rossel ${ }^{* \dagger}$ \\ Gymnase français de Bienne, Pré Jean-Meunier 1, Moutier, 2740, Switzerland
}

\begin{abstract}
Phosphate ions are socially important chemicals. They are involved in crucial processes such as for example in medicine or agriculture. However, their sensing with a chemosensor is ardous due to their chemical properties. In this context, a remarkable chemosensor would reveal an outstanding affinity, a high selectivity and a low detection limit in favor of an analyte. This has long been addressed in the past by chemists in synthesizing complex chemical architectures as receptors but with questionable successes. Astonishingly, here, for phosphate detection, we address this problem profiting by a simple fluorescent indicator displacement assay (FID) with only commercially available chemicals. We used cerium ammonium nitrate (CAN) combined with a fluorophore to probe phosphate ions in aqueous mediums. The inorganic complex detects phosphate ions in low millimolar concentrations either spectrophotometrically or with the naked-eye with high selectivity and affinity over other anions. To our knowledge, this is the first description of a simple sensitive, selective and high affinity cerium-based chemosensor for the fluorescent selective naked-eye detection of phosphate in aqueous medium. It proved useful for the detection of phosphate in Coca-Cola@.
\end{abstract}

\section{Introduction}

Phosphates are fundamental molecules involved in many key processes such as for example: water treatment, agriculture, medicine. [1-3] Therefore an easy to use, cheap, selective and sensitive analytical method to detect them is highly needed. [3] In this context, the development of remarkable chemosensors requires a low detection limit, high affinity and selectivity for the analytes such as in the case of antibodies for example. [3, 4] For phosphate, it is very difficult to achieve due to the large size of the anion, its hydrophilicity (Molar Gibbs energy of hydration of $\mathrm{PO}_{4}{ }^{3-}=-2763 \mathrm{~kJ} / \mathrm{mol}$ ), its multiple protonation states and the Hofmeister series, especially at physiological pHs. [2, 5]

\footnotetext{
*Corresponding author.

${ }^{\dagger}$ E-mail: thibaud.rossel@emsp.gfbienne.ch
} 
Most of the chemical receptors described in the literature present a combination of these three qualities but rarely the three together. [3, 4, 6-8] The exquisite detection of analytes depends notably on the interactions of the receptor and the analytes but also on the reporter for the detection of it such as in the case of indicator displacement assays. [4, 6, 7, 9] The reporter has intrinsic optical properties that dictates the emitted signal analyzed and the signal-to-noise ratio. [7]

Numerous chemosensors for the detection of anions based on displacement assay (DA), have been reported, but most of them use colorimetric indicators for the nakedeye detection of the analytes such as phosphate. [2, 6, 7, 10] For example, we reported on such receptors for colorimetric detection of phosphate with a dinuclear cerium inorganic complexes. [2, 11]

Even if they could offer exquisite selectivities and affinities, the sensitivity of such constructs remains modest due the spectrophotometric properties of the reporter. In order to improve the detection limit, various groups have reported DAs based chemosensors relying on fluorescent indicators for various anions and applications. [4, 6-8, 12] The last development in that direction is an intramolecular IDA. [7] However, very few assays were reported to date for phosphate. [3]

Here, we report our efforts to develop a simple, cheap and easy to assemble fluorimetric chemosensor based on cerium (IV) combined with calcein blue (CB) forming $[\mathrm{Ce}(\mathrm{CB})]^{2+}[2]$ able to detect selectively phosphate anions with an FID in aqueous medium. The simple and cheap chemosensor is easy to assemble and composed of commercial chemicals, has high sensitivity due to fluorescence properties and excellent selectivity for phosphate ions over other anions. Additionally, it shows high affinity for phosphate. Finally, we reveal, as proof of principle, that our complex can be used to detect phosphate ions in complex samples such as in Coca-Cola@. [13]

\section{Materials and methods}

\subsection{Complex synthesis}

Dissolving calceine blue (CB, $250 \mu \mathrm{M},(\mathrm{A}))$ and cerium ammonium nitrate (CAN, $250 \mu \mathrm{M}$ ) in 2-[4-(2-hydroxyethyl)-1-piperazinyl]ethanesulfonic acid (HEPES, $10 \mathrm{mM}$, $\mathrm{pH}=7.4)$ formed $[\mathrm{Ce}(\mathrm{CB})]^{2+}(250 \mu \mathrm{M},(\mathbf{B}))$, which is water-soluble and pale yellow at working micromolar concentrations (see Figure 1). [14] Screening of various pHs from 5 to 7 allowed us to concluede that $\mathrm{CB}$ in insoluble and therefore no complex formation was observable with CAN. Trying to form the complex $[\mathrm{Ce}(\mathrm{CB})]^{2+}$ in pure water or in see water only, displayed the same conclusion. We therefore selected $\mathrm{pH}=7.4$ for the continuation of our study since $\mathrm{CB}$ is soluble at that $\mathrm{pH}$ as described in the litterature.

In the next step, we hypothesized that $[\mathrm{Ce}(\mathrm{CB})]^{2+}$ complex could be used to assemble a receptor for phosphate derivatives, exploiting metal-ligand interactions for selective target recognition. [5] To the best of our knowledge, this mononuclear complex has never before been described in the literature as a selective FID-chemosensor for phosphate derivatives. We chose the reported calcein blue (CB), a fluorescent dye, as the fluorigenic indicator for the sensor, due to its described coordination to metal complexes, especially 
to lanthanides. [14]

A
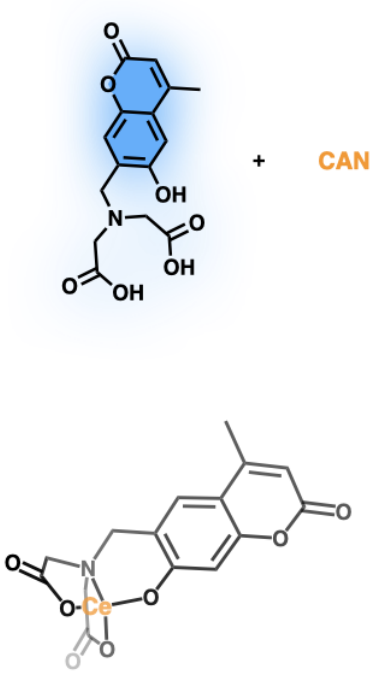

B
B

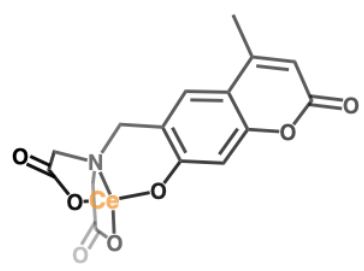

FIGURE 1: The proposed multi-step reaction mechanism presenting the fluorescent indicator displacement assay based on $\mathrm{CB}$ (A) blue added to cerium ammonium nitrate (CAN) forming $[\mathrm{Ce}(\mathrm{CB})]]^{2+}(\mathbf{B})$ at $250 \mu \mathrm{M}$ in HEPES $\mathrm{pH}=7.4$ for the detection of phosphate in $10 \mathrm{mM}$ HEPES $\mathrm{pH}=7.4$.

\subsection{Fluorescent indicator displacement assay}

$\mathrm{CB}$ (see Figure $1(\mathbf{A})$ ) which is fluorescent at $\mathrm{pH}=7.4$ is quenched when coordinated to a metal. [14] Therefore, the displacement of the receptor-bound calcein blue by phosphate anions is communicated visually under the UV lamp $(254 \mathrm{~nm})$ as well as being readily measured spectrophotometrically via fluorescence (see figure 2). The competition assay developed is illustrated schematically in figure 1 . The sensing ensemble was prepared by simply mixing CAN and CB in a 1:1 molar ratio in an aqueous solution of $10 \mathrm{mM}$ HEPES buffer $\mathrm{pH}=7.4$, resulting in a non-fluorescent complex.

In the next step, we titrated CAN with CB (visible as fluorescent blue) at $\lambda_{e x}=350 \mathrm{~nm}$ and $\lambda_{e m}=450 \mathrm{~nm}$. Out of the titration we concluded that the inflection point at 1 equivalent of CAN versus CB confirms the formation of a defined 1:1 non-fluorescent complex. The calculated affinity constant (see supporting information) is $3.98 \times 10^{4} \mathrm{M}^{-1}$, which is in good agreements with other similar described systems. $[2,14]$ The addition of phosphate anions to the aqueous solution of this violet ensemble resulted in the appearance of fluorescence (See Figure Figure 2). 
a)

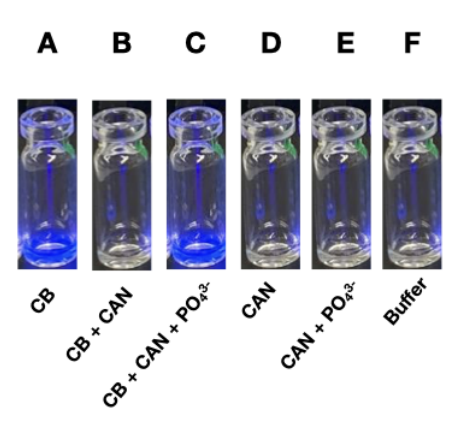

b)

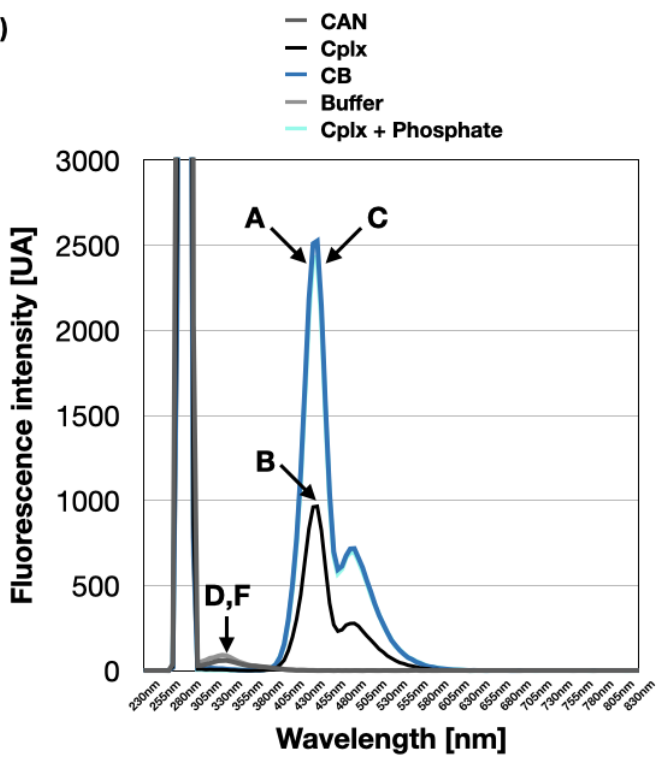

FIGURE 2: a) Addition of calcein blue (A, CB, $250 \mu \mathrm{M})$ that is fluorescent under the UV lamp to cerium ammonium nitrate $(\mathrm{CAN}, 250 \mu \mathrm{M})$ allows quenching of the fluorescence b) Addition of phosphate $(250 \mu \mathrm{M})$ to the complex $[\mathrm{Ce}(\mathrm{CB})]^{2+}$ allows a fluorescent indicator displacement assay allowing liberation of $\mathrm{CB}$ presented in the fluorescence spectras of the following vials at $\lambda_{e x}=280 \mathrm{~nm}$ and $\lambda_{e m}=450 \mathrm{~nm}$.

\subsection{Selectivity of the $[\mathrm{Ce}(\mathrm{CB})]^{2+}$ for anions}

The present sensor exhibits excellent selectivity towards phosphate ions over other anions, including pyrophosphate and sulfate ions (See Figure 3 ). To our knowledge, $[\mathrm{Ce}(\mathrm{CB})]^{2+}$ is the first fluorometric sensor based on cerium to date that can detect phosphate ions with high selectivity in an aqueous medium. Sensors that can detect analytes by fluorescence, is of particular interest due to their high sensitivity. The use of the present ensemble for such a purpose is demonstrated in Figure 3: the quenched fluorescence is recovered only when phosphate ion was added to the aqueous solution of the ensemble, whether all other anions tested failed to cause this remarkable fluorescent change even pyrophosphate remarkably (see Figure 3).

\subsection{Affinity constant determination of $[\mathrm{Ce}(\mathrm{CB})]^{2+}$ for phosphate}

In order to determine the association constant of phosphate and the stoichiometry for $[\mathrm{Ce}(\mathrm{CB})]^{2+}$, we carried out a titration (see supporting informations). At a 1:1 mixture $[\mathrm{Ce}(\mathrm{CB})]^{2+}$ versus $\mathrm{PO}_{4}{ }^{3-}$ a maximum of fluorescence is reached and the calculated association constant of phosphate to cerium (IV) is $\mathrm{K}_{a s s}=3.98 \times 10^{7} \mathrm{M}^{-1}$, which is 
a)

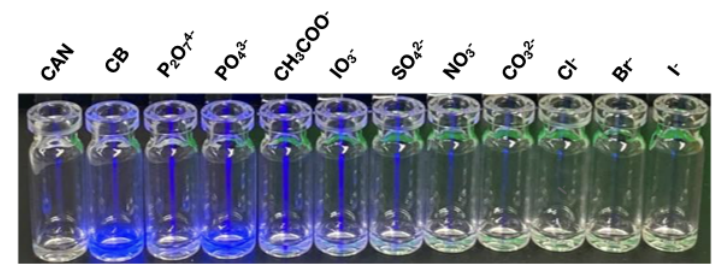

b)

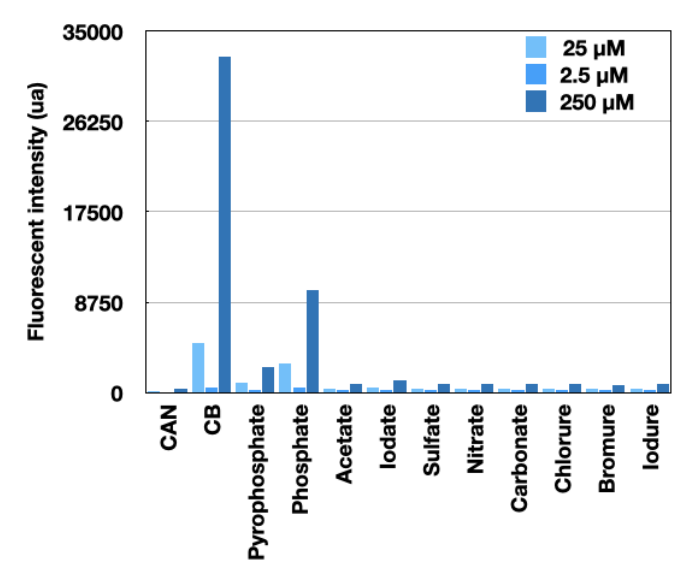

c)

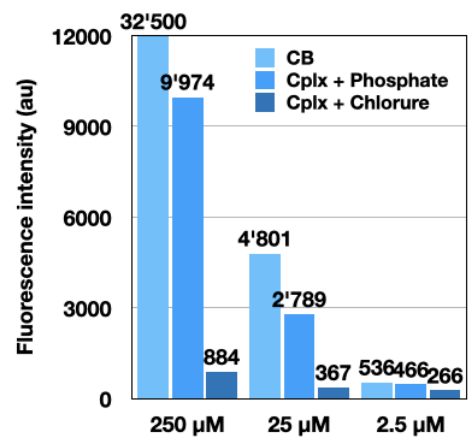

FIGURE 3: a) Screening of $[\mathrm{Ce}(\mathrm{CB})]^{2+}(250 \mu \mathrm{M}$ in HEPES $10 \mathrm{mM}$ at $\mathrm{pH}=7.4$, aqueous solution) in the presence of various anions ( $1.25 \mathrm{mM}, 5$ time excess) and exposed to a UV lamp at $254 \mathrm{~nm} \mathrm{~b}$ ) Fluorescence measurement of the mixture of $[\mathrm{Ce}(\mathrm{CB}) \text { (anions) }]^{2+}(250$ $\mu \mathrm{M}$ ): from left to right exposed to various anions; CAN, CB, $\mathrm{Na}_{2} \mathrm{P}_{2} \mathrm{O}_{7}, \mathrm{Na}_{3} \mathrm{PO}_{4}$, $\mathrm{CH}_{3} \mathrm{COONa}, \mathrm{NaIO}_{3}, \mathrm{NaSO}_{4}, \mathrm{NaNO}_{3}, \mathrm{Na}_{2} \mathrm{CO}_{3}, \mathrm{NaCl}, \mathrm{NaBr}, \mathrm{NaI}\left(\lambda_{e x}=350 \mathrm{~nm}\right.$ and emission scan optimum: $\left.\lambda_{e m}=450 \mathrm{~nm}\right) \mathrm{c}$ ) Detection limit of $[\mathrm{Ce}(\mathrm{CB})]^{2+}$

at least 1000 times higher than similar described systems for detection of phosphatederivatives [5] and similar to a colorimetric dinuclear cerium sensor that we already reported in the literature. $[2,11]$ To our knowledge, this is to date the best simple system for selective naked-eye based phosphate recognition with a mononuclear cerium complex.

\subsection{Detection limit}

Investigation of the detection limit of $[\mathrm{Ce}(\mathrm{CB})]^{2+}$ allowed us to observe that our receptor detects phosphate at a concentration of $25 \mu \mathrm{M}$. However, the measured signal at a concentration of $2.5 \mu \mathrm{M}$ is still acceptable (signal-to-noise of 1.75 times) and allows to conclude that our sensor has a detection limit in the low micromolar range. It ranks it to the best system described to date for the detection of phosphate based on a metal based DA. [3]

\subsection{Mechanism of detection}

In order to understand the disassembly of $[\mathrm{Ce}(\mathrm{CB})]^{2+}$, we hypothesized that the low solubility $\left(\mathrm{S}=2,915 \cdot 10^{-34} \mathrm{M}\right)$ of cerium phosphate might generate a precipitation. We 
therefore prepared a solution of CAN in water $(0.1 \mathrm{M})$ and a solution of sodium phosphate $(0.1 \mathrm{M})$ in water. The mix of the two solution in a 1:1 ratio generated a precipitant that we interpreted as $\mathrm{Ce}_{3}\left(\mathrm{PO}_{4}\right)_{4}$ (See Figure 4 a) suggesting the high affinity of cerium for phosphate. Additionally, to understand at micromolar concentration the behaviour of phosphate, we titrated cerium with phosphate and recorded phophorus NMRs. The disappearance of the signal suggest that even at that concentration the phosphate precipitates in the presence of cerium (see supporting information).

\subsection{Phosphate detection is Coca-Cola $\odot$}

Finally, we investigated the possibility to detect phosphate in Coca-Cola $\bigcirc$. The literature gives a concentration of phosphate in this drink of: $5578 \mu \mathrm{M}$. [13, 15] In order to do so, we diluted a sample of degassed Coca-Cola (C) (50 $\mu \mathrm{L}$ in $450 \mu$ HEPES $100 \mathrm{mM}$ $\mathrm{pH}=7.4)$. We then added a sample of diluted Coca-Cola $\odot$ to a $250 \mu \mathrm{M}$ solution of $[\mathrm{Ce}(\mathrm{CB})]^{2+}$ and measured the appearance of fluorescence. Using a calibration curve we obtained a concentration of phosphate of: $2500 \pm 32 \mu \mathrm{M} \mu \mathrm{M}$ (See Figure 4 and Table 1). Albeit the concentration determined by our assay is almost two times lower than the chromatographic determination reported in the literature [13], we can conclude that our system can measure phosphate with a good precision. One can easily imagine that the complex composition of Coca-Cola $\odot$ can interfere with the detection. In this context, we can conclude that our system is robust even in complex samples.

TABLE 1

Fluorescence values average of triplicates

\begin{tabular}{llll}
\hline Sample & $\begin{array}{l}\text { Fluorescence } \\
{[\mathrm{UA}]}\end{array}$ & $\begin{array}{l}\text { Standard } \\
\text { deviation }\end{array}$ & $\begin{array}{l}\text { Determined concentra- } \\
\text { tion of phosphate }\end{array}$ \\
\hline$[\mathrm{Ce}(\mathrm{CB})]^{2+}$ & 673 & 22 & - \\
$\mathrm{CB}$ & 2915 & 51 & - \\
{$[\mathrm{Ce}(\mathrm{CB})]^{2+}+$ Phosphate } & 1080 & 26 & $250 \mu \mathrm{M}$ \\
$(1 \mathrm{eq})$. & & & \\
$\begin{array}{l}{[\mathrm{Ce}(\mathrm{CB})]^{2+}+\quad \text { Coca- }} \\
\mathrm{Cola} \odot\end{array}$ & 1032 & 32 & $\begin{array}{l}2500 \pm 32 \mu \mathrm{M}(\mathrm{Theo}- \\
\text { ritical }=5578 \mu \mathrm{M})\end{array}$ \\
\hline
\end{tabular}

\section{Conclusion}

In conclusion, we have described a simple assay for the detection of phosphate ions in an aqueous medium. The assay is based on commercially available chemicals (cerium salts and a fluorescent indicator), and it allows quantifying phosphate in the low micromolar concentration range by fluorescence measurements. The interference of common anions is remarkably low. With a detection limit of around $2.5 \mathrm{mM}$, our system is more sensitive than some of the best spectrophotometric methods described so far. However, it is very easy to perform and it requires no prior synthesis. The high affinity constant of cerium to phosphate in also the best described in the literature do date for a mononuclear complex. First evidence for the utility of our phosphate assay was provided by the successful anal- 
a)

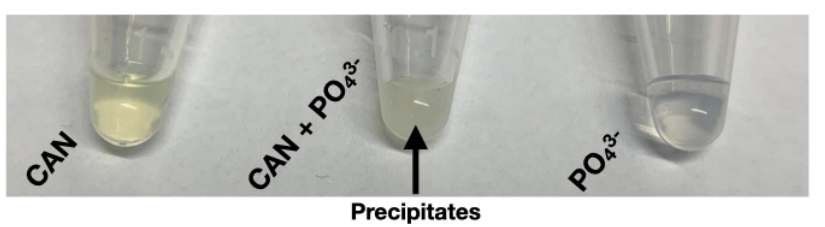

b)

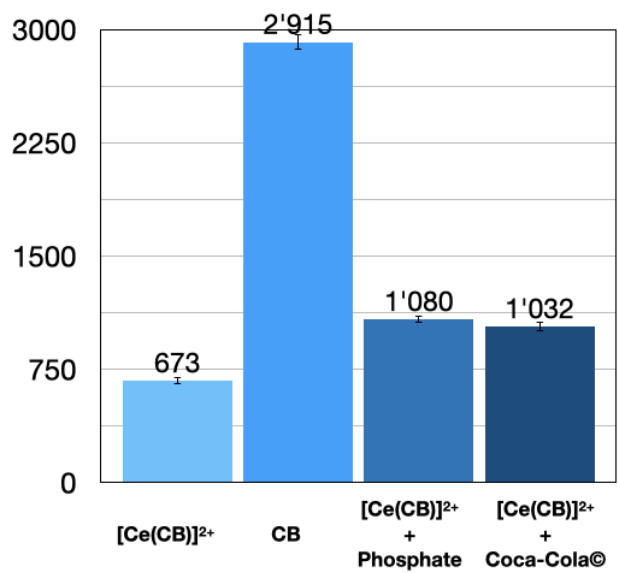

c)

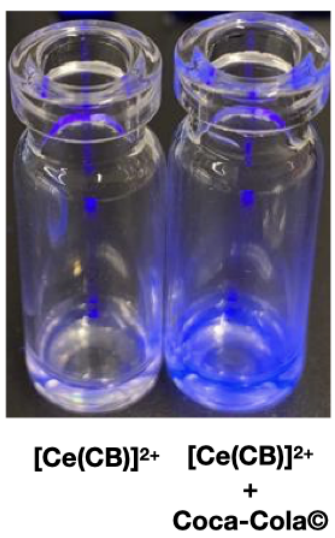

FIGURE 4: a) Precipitation of cerium phosphate when CAN dissolved in $0.1 \mathrm{M}$ in water is mixed with a $0.1 \mathrm{M}$ solution of sodium phosphate in water. b) Detection of phosphate in Coca Cola $(\odot)$ with $[\mathrm{Ce}(\mathrm{CB})]^{2+}\left(\lambda_{e x}=350 \mathrm{~nm}\right.$ and $\lambda_{e m}=450 \mathrm{~nm}$, gain 50) c) Visual detection of phosphate present in Coca-Cola $\odot$, a $250 \mu \mathrm{M}$ solution of $[\mathrm{Ce}(\mathrm{CB})]^{2+}$ in HEPES $10 \mathrm{mM} \mathrm{pH}=7.4$ is exposed to a 10 time dilution of degased Coca-Cola@ in HEPES 100 $\mathrm{mM} \mathrm{pH}=7.4$

ysis of phosphate in Coca-Cola $\odot$ products. In near futur, we would like to investigate the lanthanides serie for the detection phosphorylated molecules.

\section{Acknowledgements}

We thank Prof. Thomas R. Ward for a loan of a spectrophotometer as well as Prof. Reinhard Neier for good advices in research. We also thanks Prof. Dr. Gilles Gasser for good advices on this research. Finally, we thank the analytical service (NPAC) of the University of Neuchâtel as well as the Gymnase français de Bienne for laboratory facilities.

\section{References}

[1] X. Gao, J. Xu, B. Ye, W. Wu, and H. Zheng, Analytical Methods, 2019, 11, 26772682.

[2] T. Rossel and M. Creus, Chemical Communications, 2019, 55, 14894-14897. 
[3] A. E. Hargrove, S. Nieto, T. Zhang, J. L. Sessler, and E. V. Anslyn, Chemical reviews, 2011, 111, 6603-6782.

[4] J. Wu, B. Kwon, W. Liu, E. V. Anslyn, P. Wang, and J. S. Kim, Chemical reviews, 2015, 115, 7893-7943.

[5] M. S. Han and D. H. Kim, Angewandte Chemie International Edition, 2002, 41, 3809-3811.

[6] B. T. Nguyen and E. V. Anslyn, Coordination chemistry reviews, 2006, 250, 3118 3127.

[7] A. C. Sedgwick, J. T. Brewster, T. Wu, X. Feng, S. D. Bull, X. Qian, J. L. Sessler, T. D. James, E. V. Anslyn, and X. Sun, Chemical Society Reviews, 2020.

[8] L. You, D. Zha, and E. V. Anslyn, Chemical reviews, 2015, 115, 7840-7892.

[9] H. Wu and C. Tong, ACS sensors, 2018, 3, 1539-1545.

[10] N. Chatphueak and C. Suksai, Polyhedron, 2019, 170, 742-748.

[11] T. Rossel and M. Creus, CHIMIA International Journal for Chemistry, 2019, 73, 599-603.

[12] S. Rochat and K. Severin, Chemical Communications, 2011, 47, 4391-4393.

[13] M. A. Bello and A. G. Gonzalez, Journal of chemical education, 1996, 73, 1174.

[14] H. G. Brittain, Analytical Chemistry, 1987, 59, 1122-1125.

[15] Découvrez les ingrédients des boissons Coca-Cola, 112020. 